\title{
Ravenous wolves revisited: a systematic review of offending concentration
}

\author{
Natalie N. Martinez ${ }^{1}$, YongJei Lee ${ }^{2}$, John E. Eck ${ }^{1 *}$ and SooHyun $\mathrm{O}^{1}$
}

\begin{abstract}
Background: Numerous studies have established that crime is highly concentrated among a small group of offenders. These findings have guided the development of various crime prevention strategies. The underlying theme of these strategies is that by focusing on the few offenders who are responsible for most of the crime, we can prevent the greatest amount of crime with the fewest resources. Nevertheless, there has been no systematic review of the many studies, so it is possible that the accepted understanding among researchers and practitioners is based on a few prominent studies that are misleading. Further, we do not know how concentrated crime is among offenders, given the variety of ways researchers report their findings. This paper systematically reviews this literature and uses meta-analysis to determine how confident we can be that crime is concentrated among a few offenders.
\end{abstract}

Methods: We first systematically reviewed the literature and found 73 studies on the concentration of crime among offenders. From those studies, we identified 15 studies on the prevalence of offending and 27 studies on the frequency of offending that provided data suitable for analysis. We then performed a meta-analysis of those studies to examine how crime is concentrated among the worst offenders and how that concentration varies between different types of offenders.

Results: We found that crime is highly concentrated in the population and across different types of offenders. Little variation in concentration exists between youths and adults or between American offenders and those from other countries. We found more variation between males and females in the concentration of offending, though we believe this may be due to the more limited data on female offenders.

Conclusions: The systematic review and meta-analysis we present here is the first study of its kind on offending concentration. This is an important step in closing this gap in the crime prevention literature, but we encourage making updates to this systematic review as new literature becomes available, and using alternate methods of summarizing these studies that could challenge these findings.

Keywords: Crime concentration, Offending, Systematic review, Meta-analysis

\section{Background}

If crimes were equally distributed in society, then $10 \%$ of all offenders would account for $10 \%$ of all crimes, $20 \%$ of offenders would account for $20 \%$ of all crimes, and so on. Decades of research on offenders has shown that this is not the case. In fact, those studies have repeatedly found that the distribution of offending is skewed and that crime is highly concentrated among a small proportion

\footnotetext{
*Correspondence: john.eck@uc.edu

1 School of Criminal Justice, University of Cincinnati, Cincinnati, $\mathrm{OH}$ 45221, USA

Full list of author information is available at the end of the article
}

of offenders (e.g., Elonheimo et al. 2014; Glueck and Glueck 1950; Harer 1995; Piquero and Buka 2002; Shannon et al. 1988; Wolfgang et al. 1972). For example, Wolfgang et al. (1972) found that 6\% of the males in the 1945 Philadelphia birth cohort accounted for about $52 \%$ of all the police contacts; Sampson and Laub (2003) found that less than $3 \%$ of the Boston males in their sample were responsible for $51 \%$ of arrests after age 31; Harer (1995) found that about 6\% of federal parolees accounted for 39\% of all rearrests; and Ambihapathy (1983) found that about $8 \%$ of female offenders in Ottawa, Ontario accounted for about $36 \%$ of the arrests among that 
group. As these examples illustrate, studies that provide concentration statistics do not necessarily report them using the same benchmarks (e.g., 5,10 , or $20 \%$ of offenders), and it appears that the concentration of crime can vary between studies due to differences in their samples' characteristics.

So then, just how concentrated is offending? The answer to our question may become clearer if we turn our attention to cumulative distributions of offending. Cumulative distributions provide a count of the crimes committed by each of the individuals in a cohort (or sample), who can then be ranked in declining order of the number of crimes they have committed. When graphing this distribution, the horizontal $(\mathrm{x})$ axis is measured in percentages, so the leftmost value represents the most crime-involved percentage of individuals (e.g. the "worst" $1 \%$ ) and the rightmost value represents $100 \%$ of the group being studied. The points on the vertical (y) axis represent the percentage of all crimes committed by a given percentage of offenders along the $x$ axis. A graph of the distribution of offending concentration would resemble a reclining letter "J", with the tallest bars at the leftmost portion of the graph that gradually flatten out when moving toward the right (see Eck et al. 2007).

Spelman (1986) compared J-curves he constructed from the cumulative distributions of offending from four studies (two Philadelphia cohorts plus London and Racine cohorts). Although these studies differed in their locations, years, and methods, Spelman (1986) found that the curves from the different studies were very similar in shape. Across the four studies, the $10 \%$ of offenders most involved in crime accounted for about $40 \%$ of all offenses.

Criminologists and practitioners have long relied on the principle of crime concentration to guide crime prevention strategies. Through selective incapacitation, for example, the offenders responsible for the most crimes receive the longest sentences while other offenders receive shorter ones. By focusing resources on those offenders who contribute the most to the crime problem, selective incapacitation can be an effective strategy for preventing future crime as well as minimizing prison operating costs (Auerhahn 1999; Greenwood and Abrahamse 1982). Another example comes from the principles of effective rehabilitation, which hold that treatment is most effective at preventing crime when its intensity matches the offender's recidivism risk level (Gendreau 1996), and offenders at the greatest risk of recidivating benefit most from intense rehabilitation programs (Lowenkamp and Latessa 2004). Finally, situational crime prevention efforts are aimed at changing offenders' perceptions about the risks and rewards of crime opportunities (Clarke 1997). If a few offenders are responsible for most of the crime, then blocking opportunities can greatly reduce crime by changing these offenders' perceptions about its benefits.

Despite the large number of studies published on offenders and the importance of repeat offending to crime prevention, researchers have not synthesized this research. The lack of a systematic review creates two potential problems. First, our understanding of crime concentration among offenders maybe biased by the findings of a few prominent studies, because we may have ignored contradictory findings from lesser known studies. Even if our understanding of offending concentration is reasonably correct, we neither know how much this concentration varies across different groups, nor can we estimate the average concentration. The purpose of this paper is to close these gaps in the literature. We aim to gain insight on how concentrated crime is when we consider all the studies on this topic, how much variation exists in crime concentration among the worst offenders, and how crime concentration compares across the different groups that different researchers have studied.

\section{The literature on offending concentration}

Evidence of crime concentration among offenders dates back many decades. For example, Shaw and McKay (1942) mapped the home addresses of boys arrested in Chicago. Only one quarter of Chicago's boys lived in the areas of the city with the highest juvenile arrest rates yet boys from these areas accounted for $50-60 \%$ of all the boys arrested during the years they studied. Shaw and McKay (1942) focused on the number of offenders arrested rather than the number of arrests per offender, but their results nevertheless demonstrate that offending is not equally distributed.

Scholarly interest in quantifying offending behavior continued with Glueck and Glueck's research on delinquent boys in Boston. The boys in Glueck and Glueck's (1950) sample received between one and ten court convictions, and they counted the number of boys convicted in court once, twice, and so on for all 500 offenders. This publication provides an early example of the crime concentration statistics needed to create a cumulative distribution of offending. Unfortunately, their critics labeled the Gluecks' body of research atheoretical because it focused on individual criminogenic traits as causes of criminality, which contrasted with the criminology field's emphasis on social causes of crime at the time (Cullen 2011). Though forced into the criminological shadows for many years, the Gluecks' work nevertheless laid the groundwork for the later criminal career research that brought attention to the concentration of offending.

A discussion about crime concentration must define the terms used to measure it. Two terms used in the literature to describe offending concentration are prevalence 
and frequency. Prevalence of offending refers to the proportion of people in a population who engage in crime or delinquency (Farrington 2015; Rocque et al. 2015b; Tillman 1987) while frequency refers to the number of times an individual offends (Farrington 2015; Tillman 1987). Thus, prevalence statistics describe groups that comprise both non-offenders and offenders whereas frequency statistics describe only the behavior of offenders. In 1972, Wolfgang and his colleagues published Delinquency in a Birth Cohort, a landmark study on offending. Wolfgang et al. (1972) analyzed the juvenile police contact data for a birth cohort that included all boys born in Philadelphia in 1945 and still residing there 10 years later. As mentioned earlier, Wolfgang et al. (1972) found that a small number of high-frequency offenders in the cohort were responsible for about half of all the police contacts. Referred to in the study as "chronic" offenders, this small number of boys represented $6 \%$ of the entire cohort (an indicator of the prevalence of offending among all boys in the cohort) and $18 \%$ of the offenders in the cohort (and indicator of the frequency of offending among delinquents). The statistics on chronic offenders are the statistics most often cited from their study, but Wolfgang et al. (1972) provided statistics on the full distribution of offending in the cohort as well.

Wolfgang et al's (1972) identification of a small group of high-frequency offenders renewed interest in criminal career research. Similar studies conducted on birth cohorts in Wisconsin (Shannon et al. 1988), Denmark (Van Dusen and Mednick 1984), Puerto Rico (Nevares et al. 1990), and Sweden (Wikström 1990), for example, have been published over the years. Birth cohort studies are ideal because they represent a population of individuals, but prevalence and frequency statistics do exist for samples of individuals as well (e.g., Brame et al. 2004; Liu et al. 1997; Piquero and Buka 2002; Piquero et al. 2007).

Offending concentration studies differ widely in the types of people they study, the measures of crime they use, and the terminology they use to describe offending concentration. Some studies have focused only on males (e.g., Glueck and Glueck 1950; Tracy et al. 1990; Van Dusen and Mednick 1984; Wolfgang et al. 1972), only on females (e.g., Warren and Rosenbaum 1986) or both (e.g., Hamparian et al. 1978; Harer 1995; Nevares et al. 1990; Shannon et al. 1988). Likewise, many studies have focused exclusively on juveniles (e.g., Nevares et al. 1990; Wolfgang et al. 1972), and to a lesser extent only on adults (e.g., Sampson and Laub 2003). The measures of crime used in offending concentration studies usually range from arrests (e.g., Ambihapathy 1983; Brame et al. 2004; Fry 1985; Tillman 1987) and contacts with police (e.g., Nevares et al. 1990; Van Dusen and Mednick 1984; Wolfgang et al. 1972) to charges (e.g., Collins and Wilson
1990) and convictions (e.g., Carrington et al. 2005; Farrington and Maughan 1999; Piquero et al. 2007), but also include combining all offending into one generic "offense" measure (e.g., Cernkovich et al. 1985; Farrington et al. 2003; Piquero and Buka 2002). However, a few studies have used other measures of crime, like the number of court sentences and legal punishments (Liu et al. 1997), jail bookings (Yunker et al. 2001), and police investigations (Piquero et al. 2008).

The way researchers define the worst offenders varies from study to study. Wolfgang et al. (1972) referred to them as chronic offenders, which they defined as any boy responsible for at least five police contacts. Several studies have followed Wolfgang et al's (1972) example and defined chronic offenders in their samples as individuals responsible for at least five offenses (e.g., Ambihapathy 1983; Carrington et al. 2005; Collins 1987; DeLisi and Scherer 2006; Liu et al. 1997; Piquero and Buka 2002; Piper 1983; Piquero et al. 2008; Shannon et al. 1988; Van Dusen and Mednick 1984). However, this definition of the worst offenders is not the same in all studies. Some studies have referred to offenders as chronic if they were responsible for at least three offenses (e.g., Mednick et al. 1984; Nevares et al. 1990; Tillman 1987), at least four offenses (e.g., Schumacher and Kurz 2000), at least nine offenses (e.g., Farrington and Maughan 1999), at least 15 offenses (e.g., Skrzypiec et al. 2005), or a mixed number of offenses (e.g., Sampson and Laub 2003; ${ }^{1}$ Yunker et al. $2001)^{2}$. Still others make no such distinction between offenders in terms of their frequency (e.g., Beaver 2013; Beck and Shipley 1987; Brame et al. 2004; Collins and Wilson 1990; Elonheimo et al. 2014; Glueck and Glueck 1950; Harer 1995; Piquero et al. 2007; Warren and Rosenbaum 1986). As these examples illustrate, the concept of chronic offending is arbitrarily defined in the literature. In this study, we focus not on offenders who have committed a minimum number of crimes, but rather on the worst offenders in the distribution. We define the worst offenders as those with the highest frequency of offending, and we divide them into deciles to describe the variation in the concentration of crime among them (we discuss this more in "Analysis" section).

\section{Environmental criminology and offending concentration}

Offenders are the central focus of traditional criminology, which attempts to explain involvement and desistance from crime through differences in offenders' cognitive,

\footnotetext{
${ }^{1}$ Sampson and Laub (2003) defined chronic offenders as the 10 percent highest frequency offenders.

${ }^{2}$ In Yunker et al's (2001) report, chronic offenders included individuals with at least three felony convictions, at least five convictions for any crime, or at least ten jail bookings.
} 
social, and moral development (Lilly et al. 2015). In contrast, environmental criminology focuses on crime events and the factors that create opportunities for those events to occur (Clarke 2004; Wilcox et al. 2012). While traditional criminology focuses exclusively on offenders, environmental criminology acknowledges that victims, guardians, and other third-party actors play an important role in facilitating or blocking opportunities for crime, and many crime prevention strategies focus on the actions of these other actors (Scott 2005). Nevertheless, offenders are still critically important in environmental criminology because it is the offender's perceptions of opportunity that matters (Clarke 1997). Even though others may influence their decisions, it is the offender who ultimately chooses to commit crime. Consequently, the concentration of crime among offenders should be of equal importance to environmental criminology as the concentration of crime among places and victims. In particular, if crime is highly concentrated among relatively few offenders, then this implies that few individuals recognize that suitable crime opportunities exist. It also implies that successful situational crime prevention efforts must disproportionately affect these high-frequency offenders.

\section{Purpose of the study}

Spelman and Eck (1989) emphasized the value of understanding crime concentration for developing effective crime prevention. Recognizing that crime is highly concentrated among a small number of "ravenous wolves" (Eck 2001; Spelman and Eck 1989) can help to reduce crime by guiding strategies that remove opportunities for offending among this group. However, we know of no other publications since Spelman (1986) and later Spelman and Eck (1989) that have analyzed the cumulative distribution of offending across multiple studies.

After more than 25 years, we believe these efforts need an update. Our purpose in undertaking this task is to synthesize what we know from past studies about the concentration of offending, examine how crime concentration varies among the worst offenders, and compare the concentration of crime across the different offender groups that have been studied over the years. To accomplish this, we first conducted a systematic review of the literature on repeat offending and then meta-analyzed the studies we collected. In the next section, we describe how we identified and analyzed the literature on this topic.

\section{Methods}

\section{Criteria for inclusion and exclusion}

Each study we located for our systematic review had to meet three criteria before we would include it in our analysis. First, the study had to be written in English. Second, the study had to contain original empirical data describing the distribution of crime over possible offenders (as opposed to a secondary report of other scholars' findings). Third, the study had to provide data that allowed us to determine the percentage of offenders in its sample and percentage of crimes associated with those offenders. ${ }^{3}$

\section{Data sources and search strategy}

$\mathrm{We}^{4}$ conducted a systematic review of the literature on offending concentration. To find studies, we began by reviewing articles that summarized past research on repeat offending. A major theme across these publications was the distinction they gave to Wolfgang et al. (1972) as the seminal study on the concentration of offending within a population (DeLisi and Piquero 2011; Edelstein 2016; Farrington 1992; Petersilia 1980; Spelman 1986). Following the logic that subsequent studies on offending concentration would have also referenced this work, we performed a Google Scholar citation search for Delinquency in a Birth Cohort and limited our findings to works published in English. Although that search produced 1870 results, Google Scholar's algorithm limits the reviewable results to 1000 for any given search (Beel and Gipp 2009). We reviewed the titles and abstracts for these 1000 results and located 50 relevant studies for our analysis.

We recognize the possibility that some relevant studies on offending concentration may not have cited Wolfgang et al. (1972). Moreover, a search for only studies citing Wolfgang et al. (1972) would necessarily exclude any relevant studies published before it. Therefore, we located additional studies through manual searches of the literature reviews from the studies already included in our analysis. We also solicited fellow scholars who attended preliminary presentations of our analysis to recommend studies. Throughout this process, we noted frequently used keywords in relevant studies including: offender/ offending concentration, chronic offender/offending, repeat offender/offending, offender/offending prevalence, habitual offender/offending, persistent offender/offending, and recidivist/recidivism. We used the keywords to create automated search notifications of two ProQuest and

\footnotetext{
3 The studies had to provide percentages or at least raw counts of offenders and their crimes that we could use to calculate percentages.

4 The pronoun "we" is used for simplicity. The lead author was responsible for finding, reviewing, and coding offending concentration studies for the analysis. This process is the same as those used in the companion studies in this issue on crime concentration among places and victims, and the lead authors of those papers reviewed the coded data to ensure consistency between the papers (see Lee et al. 2017 and O et al. 2017).
} 
three EBSCO databases available through the University of Cincinnati Libraries to find additional studies our other search methods may have missed. ${ }^{5}$ We used an iterative process to search the databases, meaning that we repeated our searches as we identified additional relevant keywords. Many results overlapped between our various search methods, but we identified an additional 23 studies through the literature review and database searches that we did not find in the Google Scholar search.

\section{Coding protocol}

As we noted earlier, the studies eligible for inclusion had to provide data that allowed us to determine the percentage of offenders and crime. For each study's data, we constructed sets of $x-y$ ordered pairs representing a given percentage of people $(\mathrm{x})$ and their associated percentage of crime (y). For example, Wolfgang et al. (1972) calculated that $6 \%$ of boys accounted for $51.8 \%$ of all police contacts, so the ordered pair for this data point is $(6,51.8)$. We coded each data point according to whether it represented a measure of offending within a group of offenders and non-offenders, or whether it only measured the frequency of offending within a group of offenders. For example, in Wolfgang et al. (1972), the 6\% of the population of boys that accounted for $51.8 \%$ of police contacts also represented $18 \%$ of all offenders. The $x-y$ ordered pairs $(6,51.8)$ and $(18,51.8)$ represent measures of offending prevalence and frequency for these data, respectively. For simplicity, throughout this paper we refer to distributions of the former as "prevalence" and distributions of the latter as "frequency." We also coded each data point according to the study's decade of publication, offenders' gender (i.e., male or female), age (i.e., youth or adult) and location (i.e., United States or other country).

In total, we found 73 studies that provided 621 data points on offending concentration. ${ }^{6}$ However, we restricted our analysis to only those studies that provided complete crime distributions (see the next section for an explanation). Table 1 summarizes the characteristics of the studies included in our analysis. Males, youths, and people in the United States were the most common subjects of research in these studies compared to females, adults and people outside the United States.

\footnotetext{
${ }^{5}$ The ProQuest databases included Criminal Justice and Dissertations and Theses. The EBSCO databases included Academic Search Complete, Criminal Justice Abstracts, ERIC, and SocINDEX.

${ }^{6}$ We did not code studies that provided duplicate data points. For example, Piper $(1983,1985)$ provided some of the same concentration statistics on offending in the 1958 Philadelphia birth cohort. Similarly, Guttridge et al. (1983) provided some of the same statistics representing the distribution of violent offending across Danish males as Van Dusen and Mednick (1984). We coded only Piper's (1983) and Van Dusen and Mednick's (1984) findings for analysis because they provided a greater number of relevant statistics.
}

\section{Analysis}

Because this is the first meta-analysis of offending concentration, we had no guide to follow for combining the results from multiple studies. We used the visual binning tool in SPSS 21 to sort our unweighted data points ${ }^{7}$ into groups, or bins, along the $\mathrm{x}$-axis. We created 100 bins that ranged in value from 1 to $100 \%$ of offenders. We assigned data points to bins according to their $\mathrm{x}$-axis value $^{8}$ and calculated the median $y$-axis value for each bin. ${ }^{9}$ We then calculated a logarithmic curve to represent the cumulative distribution of offenders and crime (see Lee et al. 2017). Using only logarithmic curves in our analysis standardizes our comparisons of offender groups and allows us to compare crime concentration across offenders, victims, and places (see Eck et al. 2017, this issue).

Of the 73 studies we collected for the systematic review, 30 provided complete crime distributions, and 43 provided only partial distributions. Complete crime distributions were those that included at least two data points between, but not including, zero and 100\%. "Partial" crime distributions were those that included only one data point. We chose to restrict our analysis to only those studies that provided "complete" prevalence or frequency distributions of crime. We chose to do this because a single data point may not adequately represent a study's distribution, and we wanted to reduce the chance of our results being unduly influenced by studies reporting single data points. To test whether excluding partial data distributions changed the results of our analysis, we created prevalence and frequency distributions using all our data (including partial distributions) and then compared those distributions to their corresponding complete distributions (which did not include partial distributions). Figure 1 shows that there is little difference overall between the complete and partial distributions for either the prevalence or frequency of offending, as judged by the fit of a logarithmic curve to the distributions.

Researchers often compare offenders on their demographics (e.g., age, gender, and race), location (e.g., cross-national comparisons), types of offenses committed (e.g., property crime and violent crime), and crime data sources (e.g., official records and self-reports).

\footnotetext{
${ }^{7}$ We tested whether weighting our data would change our results. We weighted the $y$ value of each data point by its respective study sample size $(w)$ and then calculated the weighted median $(\widetilde{w y})$ for each bin $(i)$ as a measure of weighted central tendency. We found no substantial difference between the logarithmic curves for the weighted and unweighted data (see Appendix A). We chose to use unweighted data to simplify the interpretations of our results.

8 The Wolfgang et al. (1972) statistic referenced above is in the sixth bin along the $\mathrm{x}$-axis, which represents $6 \%$ of offenders.

9 We chose to use the median to account for (1) variation in y values at each $\mathrm{x}$-axis bin and (2) skewed y value distributions.
} 
Table 1 Characteristics of studies in the meta-analysis

\begin{tabular}{|c|c|c|c|c|c|}
\hline \multirow[t]{2}{*}{ Characteristics } & \multicolumn{2}{|l|}{ Prevalence } & \multicolumn{2}{|l|}{ Frequency } & \multirow[b]{2}{*}{$\begin{array}{l}\text { Number of studies } \\
\text { included in both }\end{array}$} \\
\hline & Number of studies & Number of ordered pairs & Number of studies & Number of ordered pairs & \\
\hline \multicolumn{6}{|l|}{ Publication decade } \\
\hline 1950-1959 & 0 & 0 & 1 & 10 & 0 \\
\hline 1960-1969 & 0 & 0 & 0 & 0 & 0 \\
\hline 1970-1979 & 1 & 3 & 2 & 8 & 1 \\
\hline 1980-1989 & 3 & 26 & 9 & 105 & 3 \\
\hline 1990-1999 & 4 & 43 & 6 & 74 & 4 \\
\hline 2000-2009 & 6 & 80 & 8 & 88 & 4 \\
\hline 2010-2014 & 1 & 2 & 1 & 3 & 0 \\
\hline \multicolumn{6}{|l|}{ Type of offender } \\
\hline Adult & 3 & 34 & 7 & 71 & 2 \\
\hline Youth & 7 & 64 & 12 & 110 & 6 \\
\hline Male & 13 & 108 & 14 & 119 & 11 \\
\hline Female & 5 & 17 & 7 & 35 & 4 \\
\hline United States & 10 & 95 & 17 & 170 & 8 \\
\hline Non-United States ${ }^{a, b}$ & 5 & 59 & 10 & 118 & 4 \\
\hline Studies analyzed & 15 & 154 & 27 & 288 & \\
\hline (Studies identified) & $(55)$ & (263) & (44) & (358) & \\
\hline
\end{tabular}

a Non-US prevalence data included studies from: England (2), Denmark (1), Finland (1) and Puerto Rico (1)

b Non-US frequency data included studies from: Australia (2), Canada (2), England (2), China (1), Denmark (1), Europe (1), and Puerto Rico (1)

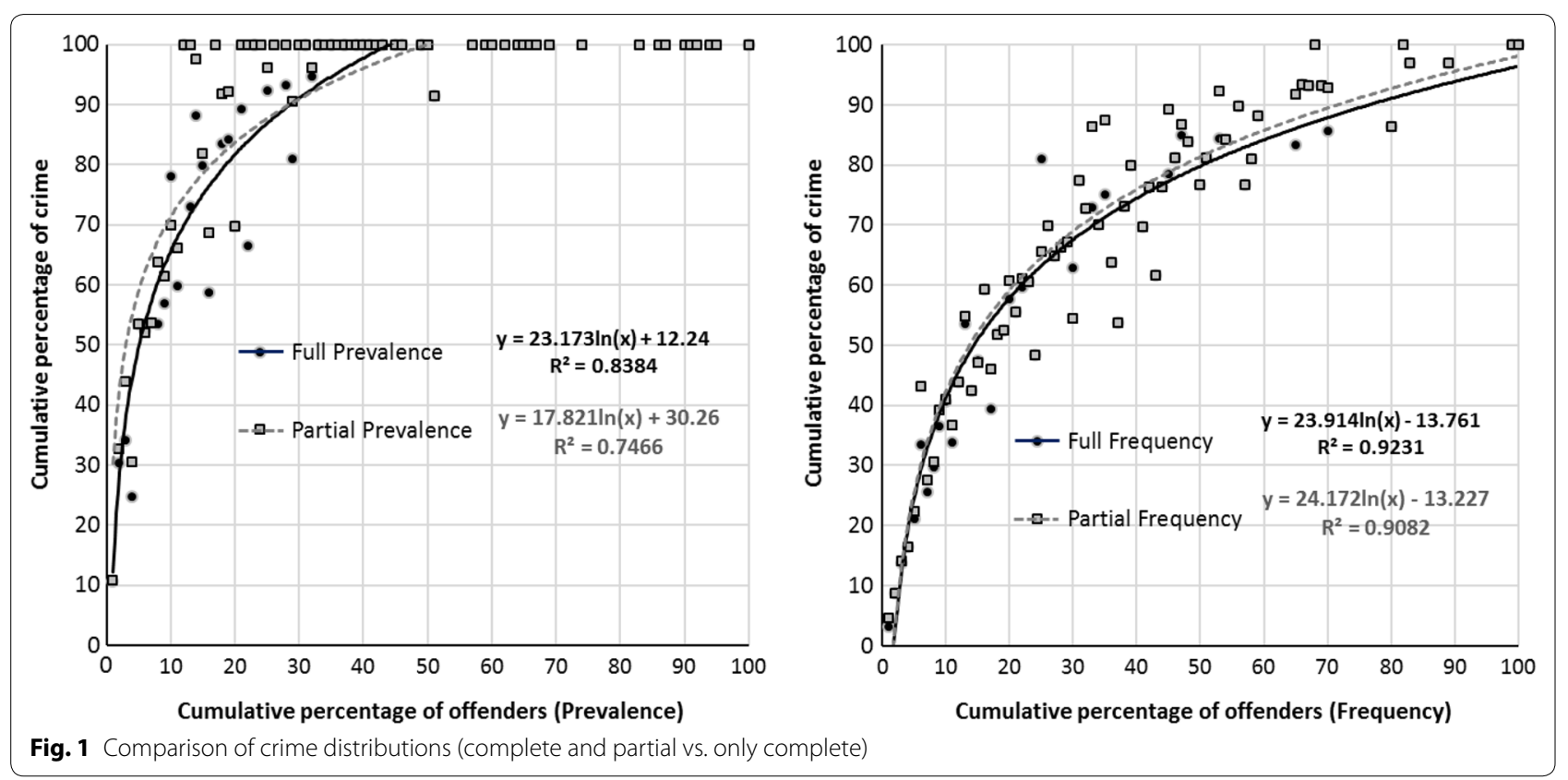

Making such comparisons across studies requires that (1) offender and offense characteristics are measured the same way and that (2) a sufficient number of studies exist with data on those measures. The studies we collected contained many of these characteristics on offenders, but our conservative decision to focus only on complete crime distributions limited the types of comparisons available in our data. For example, comparisons of data from official records and self-reports suggest that offending prevalence and frequency differs across these 
two types of data sources (Babinski et al. 2001; Kirk 2006). Some of the studies we collected for the systematic review included self-report or official records data, but limiting our analysis to complete crime distributions excluded the self-report data on offending prevalence.

In addition to an overall analysis of the prevalence and frequency of offending across the various studies that met our inclusion criteria, we present three other comparisons. We compare the offending distributions between males and females, youths and adults, and the United States and other countries. We chose these three because we had sufficient data for these comparisons. We would have liked to make other comparisons, but we were limited by the original study authors' data collection methods and the fact that there is no standard procedure for defining characteristics and collecting data on offenders.

\section{Results}

We chose to display crime concentration by graphing the logarithmic curves created using the $x-y$ ordered pairs for our data points. Visually, a straight diagonal line from the graph's origin to the ordered pair representing $100 \%$ of the people and $100 \%$ of crime would indicate no concentration. Offending would be evenly spread across the people studied. Conversely, a curve with all percentages of crime (on the $y$-axis) greater than the cumulative percentage of offenders (on the $\mathrm{x}$-axis) shows concentration. The more the curve bows toward the upper left of the graph, the greater the crime concentration. Substantively, crime concentration is greater when fewer offenders account for a large proportion of crime.

\section{Overall offending prevalence and frequency}

We began our analysis by comparing the cumulative distributions of offending prevalence and frequency across all our studies. We calculated the prevalence and frequency curves using 154 data points from 15 studies and 288 data points from 27 studies, respectively. In Fig. 2, the solid line represents the prevalence curve and the dashed line represents the frequency curve. The prevalence curve represents the distribution of offending across a "population" containing both offenders and nonoffenders. In contrast, the frequency curve reflects the crime concentration only among individuals who have committed at least one offense (i.e., offenders). The prevalence distribution shows more crime concentration than the frequency distribution. This is expected given that offending is a rare occurrence (i.e., most people in the population do not commit crime). For example, the $10 \%$ of the most criminally-active people account for around $66 \%$ of crime, whereas the most active $10 \%$ of offenders account for around $41 \%$ of crime (see Fig. 2).

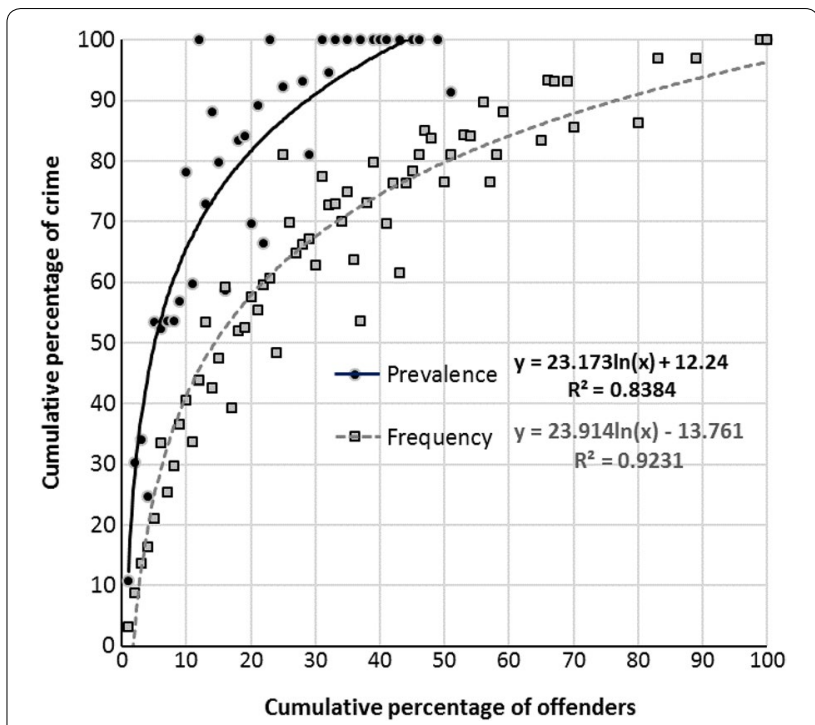

Fig. 2 Overall prevalence and frequency of offending

\section{Youths and adults}

Research has shown that involvement in offending differs between youths ${ }^{10}$ and adults. The prevalence of offending tends to reach its peak in late adolescence and then declines rapidly by early adulthood. ${ }^{11}$ This pattern is commonly referred to as the "age-crime curve" (Farrington 1986; Hirschi and Gottfredson 1983; Piquero et al. 2003). Hirschi and Gottfredson (1983) contend that the age-crime curve is invariant, meaning that the pattern of involvement is the same for all types of offenders. If the prevalence of offending follows a stable pattern that predicts a sharp decline in early adulthood, then there would be no need to examine changes in offending over the life course through criminal career research (Rocque et al. 2015a). Although youths are more likely than adults to be involved in crime, it is unclear whether the prevalence of offending differs within each group.

It is also unclear whether youths and adults differ in the frequency of their offending. Hirschi and Gottfredson (1983) claim that the frequency of offending follows the same pattern as prevalence. In other words, the sharp decline in the age-crime curve that occurs in early adulthood reflects both a decrease in

\footnotetext{
${ }^{10}$ Offenders were labeled as youths or adults based on the original studies' categorizations. Youth and adult offenders were defined differently across studies. For example, Beck and Shipley (1987) studied adult offenders age 17 and older whereas Wolfgang et al. (1972) studied youth offenders age 17 and younger.

11 Graphically, a histogram of offenders arranged in age from youngest to oldest along the horizontal axis would show a gradual increase in the prevalence of offending from childhood to late adolescence, and then a sharp decrease in prevalence among adults (see Hirschi and Gottfredson 1983).
} 
the prevalence of offending and a decrease in the frequency of offending (Piquero et al. 2003). However, the research on offending generally does not support this view (for a review, see Piquero et al. 2003). In contrast, Blumstein et al. (1988) argue that while the decline could be the result of a large proportion of offenders desisting from crime as young adults, this does not mean that those who continue to offend necessarily do so less frequently.

To examine these potential differences in offending prevalence and frequency, we used a combination of data points from studies of (1) only youths (2) only adults, and (3) both youths and adults. In the third category, we retained the data points from studies that differentiated between crimes committed by youth offenders and crimes committed by adult offenders. We estimated the prevalence curves using 64 data points from 7 studies for youths and 34 data points from 3 studies for adults. We calculated the frequency curves using 110 data points from 12 studies for youths and 71 data points from 7 studies for adults.

In Figs. 3 and 4, the dashed lines represent the youth curves and the solid lines represents the adult curves. The prevalence curves in Fig. 3 show little difference in the concentration of offending among youths and adults in the population. It appears that the worst (i.e., the most criminally active) $10 \%$ of youths account for a slightly smaller proportion of their age group's crime (about 37\%) than the most active $10 \%$ of adults (about $41 \%$ ). In Fig. 4 , we found more concentration in the frequency of offending among the adult offenders than among the youth offenders. However, the standard errors of each curve indicate that the graphs are not substantially different

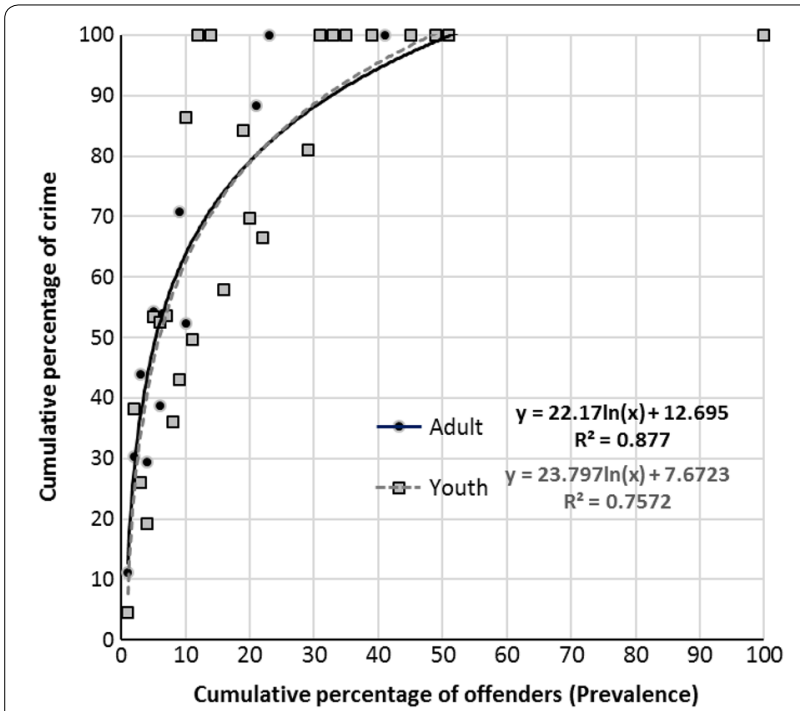

Fig. 3 Adult and youth offending prevalence

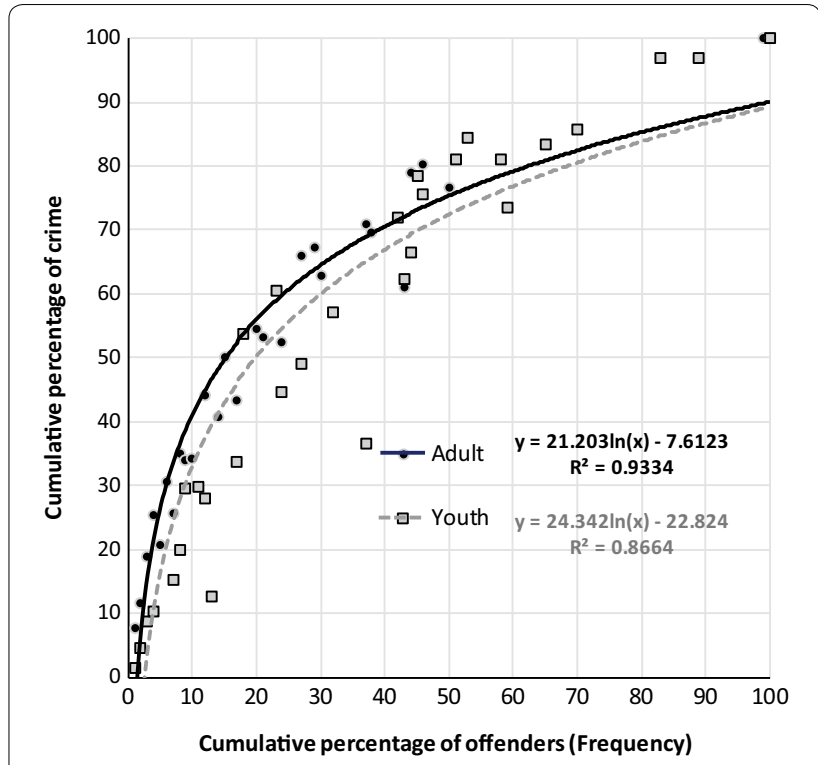

Fig. 4 Adult and youth offending frequency

from each other in terms of offending concentration (see Appendix B). Our results suggest that the prevalence and frequency of offending is similar between youths and adults.

\section{Males and females}

Males and females differ in both the prevalence and frequency of offending. Males are more likely to offend, and those who do offend tend to commit crime with greater frequency than female offenders (D'Unger et al. 2002). This would suggest that the prevalence of offending is less concentrated among the male population and that the frequency of offending is more concentrated among male offenders. To compare male and female offending, we used a combination of data points from studies of (1) only males (2) only females, and (3) both males and females. In the last category, we retained the data points from studies that differentiated acts committed by males from those committed by females. We calculated the prevalence curves using 108 data points from 13 studies for males and 17 data points from 5 studies for females. We calculated the frequency curves using 119 data points from 14 studies for males and 35 data points from 7 studies for females.

In Figs. 5 and 6, the solid lines represent the male curves and dashed lines represent the female curves. The comparison of the prevalence curves in Fig. 5 shows some difference in the prevalence of offending among males and females in their respective populations. According to our results, the prevalence of offending is somewhat more concentrated among males. This finding contradicts our expectations, as it implies that offending is more 

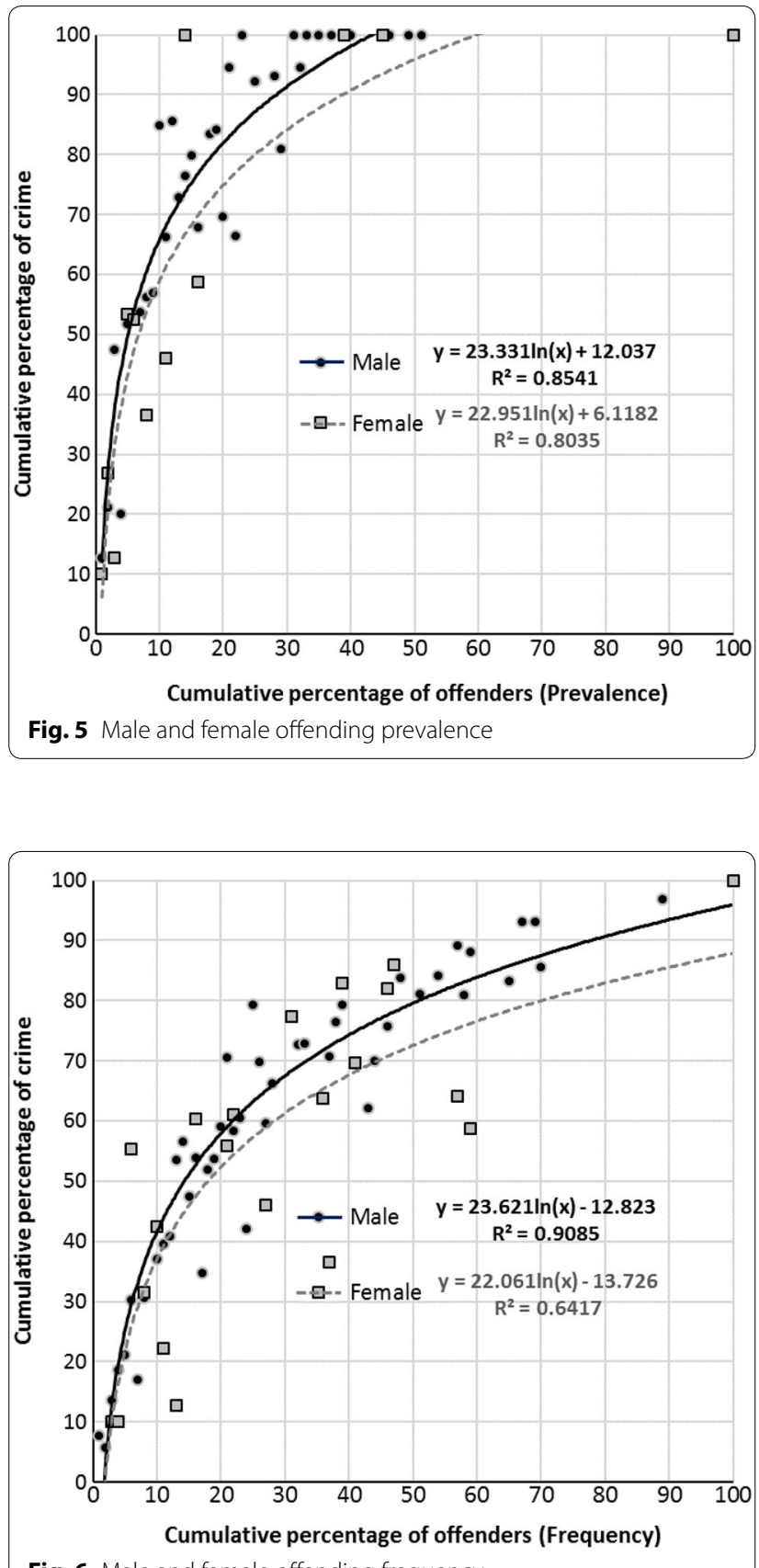

Fig. 6 Male and female offending frequency

widespread among females than among males. However, these differences are small for the males and females who are the most involved in crime. For example, the most crime-involved $10 \%$ of males account for around $66 \%$ of the crime whereas the same $10 \%$ of females account for $59 \%$ of crime. In the frequency curve comparison, we again find some difference between males and females. The frequency of offending is more concentrated among male offenders and the males who repeatedly offend are responsible for a slightly greater proportion of crime than are their female counterparts. Using the $10 \%$ of individuals who are the most involved in crime as a benchmark, this percentage of males and females account for around 42 and $37 \%$ of crime, respectively. However, given the notable disparity in numbers of studies on male and female offending, these findings must be treated with some caution, as we will discuss later in the paper.

\section{The United States and other countries}

Comparing the distributions of offending between the United States and other countries allows us to examine crime concentration across different social, cultural, and legal contexts (Farrington 2015; Farrington and Wikstrom 1994). Using Wolfgang et al's (1972) definition of chronic offenders, Rocque et al. (2015b) examined the prevalence of chronic offenders in an international sample and found that they were more common in the United States and European countries than in Latin American countries. They created a proxy for the different cultural contexts by grouping the countries into five clusters based on similarities in their social welfare states. Clustering the United States with Ireland, Rocque and his colleagues found that chronic offenders comprised 10.9\% of that sample, compared to 9.4\% ("Western Europe"), 7.8\% ("Northern Europe"), 6.2\% ("Mediterranean Europe"), 5.4\% ("Eastern and Central Europe"), and 4.2\% ("Latin America") of the other samples. Rocque et al. (2015b) noted that although these results suggest that the frequency of offending does vary across cultural contexts, the differences between these percentages are not large. Although they did not analyze the countries' data individually, and the statistics cited above describe only offenders that meet their definition of chronic, Rocque et al.s (2015b) results are still relevant to our analysis because they suggest that offending concentration does vary between nations.

We calculated the prevalence curves using 95 data points from 10 studies that used data collected in the United States and 59 data points from 5 studies that used data from other countries. We calculated the frequency curves using 170 data points from 17 studies on the United States and 118 data points from 10 non-United States studies. In Figs. 7 and 8, the solid lines represent the United States curves and the dashed lines represents the non-United States curves. The comparison of the curves in Fig. 7 shows little difference in the prevalence of offending between the United States and other countries. The $10 \%$ of people who are most involved in crime in the United States account for about $63 \%$ of the crime, whereas the same $10 \%$ in other nations account for $68 \%$ of crime, and the difference between the curves' standard errors is also small. Thus, our results suggest that 


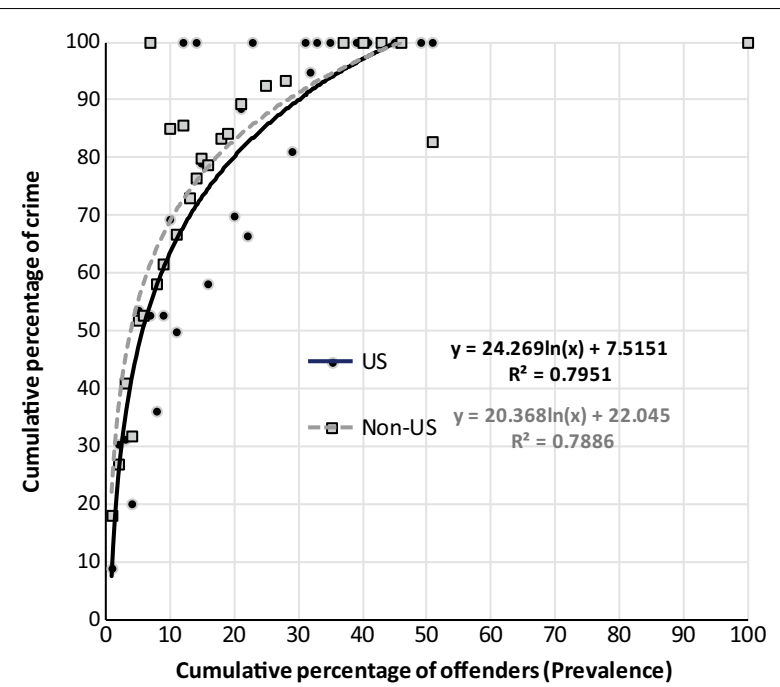

Fig. 7 United States and non-United States offending prevalence

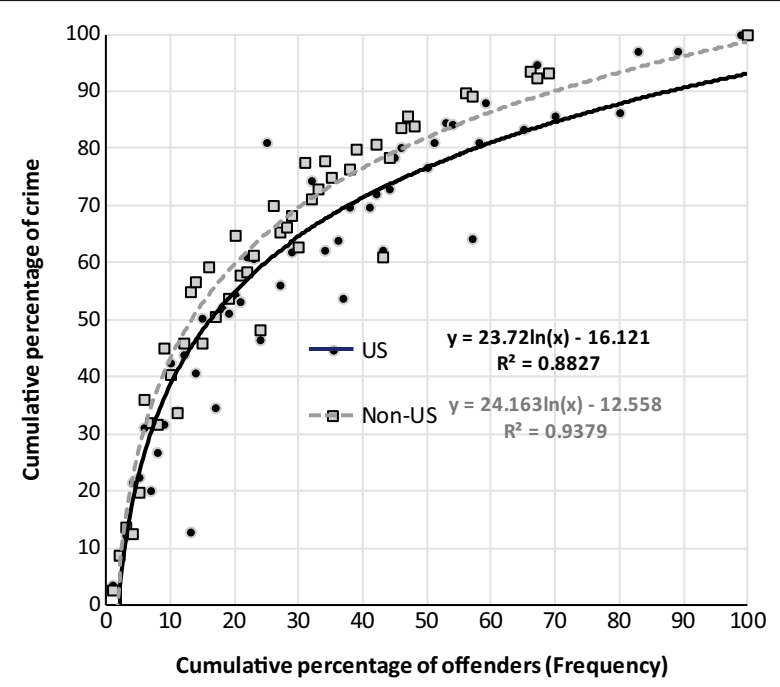

Fig. 8 United States and non-United States offending frequency

the prevalence of offending does not vary substantially between nations. The curves in Fig. 8 also show some difference in offending frequency. Offending appears to be slightly less concentrated in the United States than in other countries. Our results suggest that repeat offending is somewhat more widespread among offenders in the United States than among offenders in other nations, but the differences between the curves are small (particularly in their leftmost portions). These results seem to be consistent with the pattern in Rocque et al.s (2015b) findings. In other words, there is some variation in the concentration of offending between nations, but these differences are not substantial, and the greater amount of spread we observe in the United States data points may be due to variations in the methods used in those studies.

\section{Comparison to crime concentration "standards"}

There are several concentration benchmarks in the literature. These "standard" statistics include: (1) the worst $5 \%$ of a population (e.g., Weisburd 2015; Weisburd et al. 2004); (2) the worst 10\% of offenders (e.g., Eck 2001; Spelman 1986; Spelman and Eck 1989); and (3) the worst $20 \%$ of offenders (e.g., Clarke and Eck 2005; Koch 1998). These serve as points of similarity between ours and other concentration studies that we can use to compare our results (see Appendix B for a detailed list of these statistics for each our comparisons).

The "worst 5\%" is a crime concentration statistic often associated with places and crime in the environmental criminology literature. For example, Weisburd et al. (2004) found that about 5\% of street segments in Seattle generated about $50 \%$ of the city's police incident reports. Although this study focused on crime concentration among a population of places, recall that Wolfgang et al.s (1972) chronic offenders represented 6\% of the entire 1945 Philadelphia birth cohort and accounted for $51.6 \%$ of all its offenses. In our prevalence comparisons, we found that in the overall analysis and among youths, adults, males, and nations, $5 \%$ of each population accounted for between about 47 and $55 \%$ of crime. The concentration of crime was lower among females, with $5 \%$ of all females accounting for about $43 \%$ of crimes.

Recall that Spelman (1986) found that the worst 10\% of offenders accounted for $40 \%$ of offenses. Spelman and Eck (1989) later suggested that crime was even more concentrated among this group. They estimated that the worst $10 \%$ of offenders account for about $55 \%$ of offenses. Our overall frequency analysis shows that the worst $10 \%$ of offenders account for about $41 \%$ of crime, which is closer to the results from Spelman's (1986) analysis. Moreover, our results suggest that the worst $10 \%$ of offenders account for about $40 \%$ of crime in all of our comparisons. Across the overall, gender, age, and nation frequency comparisons, $10 \%$ of the worst offenders accounted for between 37 and $43 \%$ of offending.

The final statistic is the Pareto principle, which Italian economist Vilfredo Pareto discovered in 1897 to describe the mathematical relationship he observed between a given proportion of the population and the amount of wealth associated with those people. Pareto noted that a minority of individuals accounted for a disproportionate amount of wealth and that this relationship followed a consistent and predictable pattern (Koch 1998). The Pareto principle is often alternatively referred to in business and economics literature as the "80/20 principle," meaning that $80 \%$ of a system's outputs are due to only 
$20 \%$ of its inputs (Koch 1998). However, the $80 / 20$ principle has been discussed in the environmental criminology literature as well (e.g., Andresen 2014; Clarke and Eck 2005; Weisburd et al. 2012).

In the context of offending, Clarke and Eck (2005) invoke the $80 / 20$ principle and state that $20 \%$ of offenders account for $80 \%$ of crime. Looking again at the overall frequency distribution, our results show that $20 \%$ of offenders account for about $58 \%$ of crime. Likewise, across our other frequency comparisons, $20 \%$ of offenders account for between 52 and $60 \%$ of crime. These results seem to suggest that offending is less concentrated than other phenomena often described using the $80 / 20$ principle. However, looking instead at the prevalence of offending in the overall analysis and among youths, adults, males, and nations, $20 \%$ of each population accounts for between 79 and $83 \%$ of crime. Similar to our results regarding the worst $5 \%$ of the population, offending was somewhat less concentrated among the female offender group, with $20 \%$ of all females accounting for about $75 \%$ of crimes by women.

\section{Discussion}

Across our comparisons, crime was less concentrated among the offender-only groups (frequency) than among the populations of offenders and non-offenders (prevalence). As we noted earlier, this was an expected result and serves at least to support the reliability of our analysis. Our most interesting findings were the results of the comparisons between different offender and population groups. For youths and adults, our findings question Hirschi and Gottfredson's (1983) assumption that the prevalence and frequency of crime invariantly declines in early adulthood. If offending is less common in adulthood than in adolescence, then we would expect the prevalence and frequency of crime among adults to be more concentrated. However, our results suggest that offending is equally prevalent between these two groups and that crime is equally distributed among the most frequent offenders. The finding that offending is similarly distributed between youth and adults supports the need for criminal career research and the examination of the factors that influence fluctuations in the patterns of offending from adolescence through adulthood. As Cullen (2011) argues, criminology has long been the study of adolescent offending. However, the similarities adolescents share with adults in the distribution of offending suggest that adult offending should not be ignored in the development of crime prevention interventions.

Our gender analysis provided several findings that were inconsistent with the literature on female offenders. First, our results suggested that a greater proportion of females than males become involved in crime. Second, crime was somewhat less concentrated among the worst 5 and $20 \%$ of female offenders compared to the same proportion of offenders in the other analysis groups (i.e., males, youths and adults, United States and other nations). One explanation for these unexpected results is that our female prevalence and frequency curves are based on only 17 and 35 cumulative data points, respectively. Having few studies and data points for female offending may have influenced our findings. In other words, if female offending research was as common as male offending research, our results might be different. Compounding this potential problem is the fact that the data points for females appear more dispersed around the female curve than the data points around the male curve (see Figs. 5, 6). Thus, we are less confident that our results are valid with respect to female offending.

Across nations, involvement in crime appears to be equally prevalent although the frequency of crime in the United States appears to be slightly less concentrated among its worst offenders. Our results seem to support Rocque et al.s (2015b) finding that offending varies across different cultural contexts, but also that this variation is not large. However, the dichotomy we used to compare the United States and other nations obscures the differences between countries in the latter category and the potential influence of those differences on crime concentration.

Many of our results are also consistent with the 5, 10, and $20 \%$ markers commonly referenced in the crime concentration literature. However, our findings do underscore the importance of considering crime concentration among populations rather than restricting analysis to offender groups only. For example, the Pareto principle has been cited in the environmental criminology literature to predict that $20 \%$ of all offenders account for $80 \%$ of all crime. Based on our analysis, a more appropriate interpretation would be that $20 \%$ of all individuals in a population account for $80 \%$ of all crime (which is in line with Vilfredo Pareto's original use of the principle).

\section{Limitations}

We based our conclusions on the decisions we made in conducting our systematic review of offending and defining the inclusion criteria for our analysis. Thus, if another researcher conducted a similar review of the literature, but made different decisions at those stages, it is theoretically possible that he or she would arrive at different results. Though we are confident that our decisions are appropriate, their validity can only be assessed by replication.

We acknowledge that there are other limitations to our methods and analysis. First, because offending concentration statistics are sometimes a secondary research 
finding (e.g., not reported in titles and abstracts, but found in tables and appendices as background information), it is possible that we missed some relevant studies when conducting the systematic review. Moreover, we restricted our review to empirical studies written in English, which may have excluded some foreign language publications with relevant concentration statistics. Thus, our results should be regarded as tentative rather than conclusive statements on offending concentration.

Second, we excluded 43 studies from our analysis because they did not provide sufficient data points. One problem with excluding studies is that it limits the variation our data and thus restricts the types of comparisons we can make. Although we were limited to overall, gender, age, and nation comparisons due to the characteristics of the studies we collected, these are not the only important comparisons to make about offenders.

Third, we used only a single functional form, a logarithmic curve, to describe all our distributions. This consistency helps us to make comparisons, but it necessarily assumes there is only one functional form to describe all these data when it is possible that different groups have different functional forms. For example, it is possible in principle that male offending follows a different functional form than female offending, though we know of no theory that would support such a claim.

Fourth, using visual binning to construct the logarithmic curves was our best option to aggregate the $x-y$ ordered pairs for analysis, but in consequence, we may have lost some variation in our data. We acknowledge that with no precedent for this type of analysis, our methods leave room for improvement. We believe we have made progress toward closing a gap in the crime prevention literature by expanding upon Spelman and Eck's work, but we invite other researchers to join us in this achieving this goal.

\section{Conclusions}

This study is the first to systematically review the literature on offending concentration and use a meta-analysis to synthesize the evidence. One of our reasons for doing it was to assess whether the evidence collectively supports what criminologists have long asserted: that crime is highly concentrated among a minority of offenders. Our findings suggest that these "wolves" are indeed a small and ravenous pack. Our results also lend support to practical strategies that focus their resources on the worst offenders to prevent the most crime. These findings seem obvious, but they are nevertheless important to highlight. The meta-analysis could have just as well suggested that our long-held assumptions about offending concentration are wrong.

In this paper, we focused on addressing three questions. First, how concentrated is crime across all studies? Our results show that crime is highly concentrated among a small group of offenders, even in a heterogeneous distribution of crimes and offenders. Second, how much variation exists among the worst offenders? We examined the variation in crime concentration among the worst 5, 10 , and $20 \%$ of offenders across four different comparisons. Except for females, we found that the distribution of offending within each group is similar at these points. Third, how does crime concentration compare across different offender groups? We found few differences in the concentration of offending across the different groups we compared.

Those three questions are important for understanding the concentration of offending. But environmental criminologists are keenly aware that offenders represent only one element of the crime triangle (Clarke and Eck 2005). Decades of research has shown that crime is also highly concentrated among a small number of places (Lee et al. 2017) and victims (O et al. 2017, this issue). From a crime prevention perspective, it is just as important to evaluate the concentration of crime among offenders as it is to examine concentration among places and victims. From a practical standpoint, focusing resources where crime is most concentrated has the potential to prevent the most crime. Spelman and Eck (1989) compared crime concentration across those three domains and concluded that among the "worst" $10 \%$, crime was more concentrated among places than among offenders and victims. In a 
separate paper we compare crime concentration in these three domains to determine if Spelman and Eck's findings are still valid (Eck et al. 2017).

Our findings suggest that the implications drawn from the most prominent studies in the literature are probably sound: a few people do commit the most crimes, and among offenders, a relatively small group are responsible for most crimes. The policy implications we can draw are obvious: focus attention on the most active offenders. For situational crime prevention and related interventions, it may be worth considering why a few offenders find some targets and places very attractive, but most people, and most other offenders, do not. Do they perceive opportunities differently, or are they more exposed to attractive opportunities? Environmental criminology-based prevention and policies often do not differentiate between high-frequency offenders and sporadic offending, but perhaps they should.

\section{Authors' contributions}

This paper was conducted by a team. NNM was the lead writer for this paper, contributed to the development of the methods used, and provided expertise on offenders. YL was the lead analyst for the team and provided editorial assistance. JEE headed the team and provided overall guidance and editorial assistance. SO provided expertise on victims assisted in the development of the research methods, and provided editorial reviews. All authors read and approved the final manuscript.

\section{Author details}

'School of Criminal Justice, University of Cincinnati, Cincinnati, OH 45221, USA. ${ }^{2}$ School of Public Affairs, University of Colorado, Colorado Springs, CO 80918, USA.

Acknowledgements

Authors thank the reviewers for their useful comments.

Competing interests

The authors declare that they have no competing interests.

\section{Availability of data and materials}

Articles used in the systematic review are noted in the references. For other information regarding data, please contact the lead author.

\section{Consent for publication}

Not applicable.

\section{Ethics approval and consent to participate}

Does not apply. As a review of summary data from previously conducted research, no humans (or their tissues) participated as subjects in this research.

\section{Funding}

No funds were solicited or provided for this research.

\section{Appendices}

Appendix A: Estimated distributions of crime prevalence and frequency among offenders: a comparison of fitted lines between un-weighted and weighted $\mathrm{X}-\mathrm{Y}$ ordered pairs
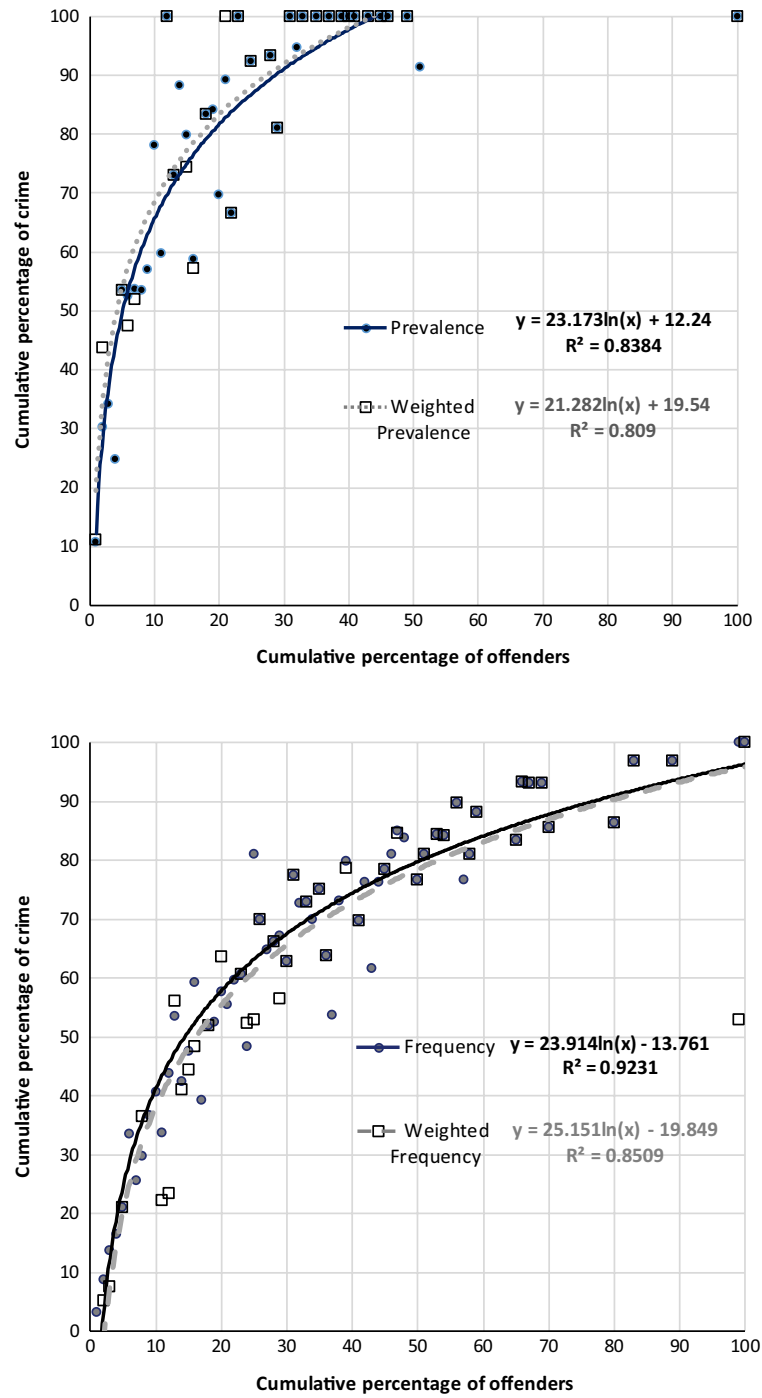

Appendix B

See Table 2. 
Table 2 Estimated coefficients and summary statistics of the model specifications in Figs. 1, 2, 3, 4, 5, 6, 7, 8

\begin{tabular}{|c|c|c|c|c|c|c|c|c|c|c|c|c|c|}
\hline \multirow[t]{2}{*}{ Figure number } & \multirow[t]{2}{*}{ Key } & \multirow[t]{2}{*}{$\mathrm{N}$ study } & \multirow[t]{2}{*}{$N(X, Y)$} & \multirow[t]{2}{*}{ Constant } & \multirow[t]{2}{*}{ Beta } & \multirow[t]{2}{*}{ Std. error } & \multicolumn{2}{|c|}{$\begin{array}{l}\text { Confidence } \\
\text { interval }\end{array}$} & \multirow[t]{2}{*}{ t-statistic } & \multicolumn{4}{|c|}{$\begin{array}{l}\text { Percentage of crime } \\
\text { explained by }\end{array}$} \\
\hline & & & & & & & & & & $5 \%$ & $10 \%$ & $20 \%$ & $50 \%$ \\
\hline \multirow[t]{4}{*}{ Figure 1} & Full prevalence & 15 & 154 & 12.24 & 23.17 & 1.67 & 19.83 & 26.52 & 13.86 & 49.5 & 65.6 & 81.7 & 100.0 \\
\hline & Partial prevalence & 55 & 263 & 30.26 & 17.82 & 1.30 & 15.23 & 20.42 & 13.73 & 58.9 & 71.3 & 83.6 & 100.0 \\
\hline & Full frequency & 27 & 288 & -13.76 & 23.91 & 0.87 & 22.17 & 25.65 & 27.50 & 24.7 & 41.3 & 57.9 & 79.8 \\
\hline & Partial frequency & 44 & 358 & -13.23 & 24.17 & 0.95 & 22.27 & 26.08 & 25.36 & 25.7 & 42.4 & 59.2 & 81.3 \\
\hline \multirow[t]{2}{*}{ Figure 2} & Prevalence & 15 & 154 & 12.24 & 23.17 & 1.67 & 19.83 & 26.52 & 13.86 & 49.5 & 65.6 & 81.7 & 100.0 \\
\hline & Frequency & 27 & 288 & -13.76 & 23.91 & 0.87 & 22.17 & 25.65 & 27.50 & 24.7 & 41.3 & 57.9 & 79.8 \\
\hline \multirow[t]{2}{*}{ Figure 3} & Adult (P) & 3 & 34 & 12.70 & 22.17 & 2.63 & 16.92 & 27.42 & 8.45 & 48.4 & 63.7 & 79.1 & 99.4 \\
\hline & Youth (P) & 7 & 64 & 7.67 & 23.80 & 2.75 & 18.30 & 29.30 & 8.65 & 46.0 & 62.5 & 79.0 & 100.0 \\
\hline \multirow[t]{2}{*}{ Figure 4} & Adult (F) & 7 & 71 & -7.61 & 21.20 & 1.11 & 18.98 & 23.42 & 19.09 & 26.5 & 41.2 & 55.9 & 75.3 \\
\hline & Youth (F) & 12 & 110 & -17.01 & 23.56 & 1.67 & 20.22 & 26.90 & 14.12 & 20.9 & 37.2 & 53.6 & 75.2 \\
\hline \multirow[t]{2}{*}{ Figure 5} & Male (P) & 13 & 108 & 12.04 & 23.33 & 1.68 & 19.97 & 26.69 & 13.90 & 49.6 & 65.8 & 81.9 & 100.0 \\
\hline & Female (P) & 5 & 17 & 6.12 & 22.95 & 3.59 & 15.77 & 30.13 & 6.39 & 43.1 & 59.0 & 74.9 & 95.9 \\
\hline \multirow[t]{2}{*}{ Figure 6} & Male (F) & 14 & 119 & -12.82 & 23.62 & 1.12 & 21.39 & 25.86 & 21.14 & 25.2 & 41.6 & 57.9 & 79.6 \\
\hline & Female (F) & 7 & 35 & -13.73 & 22.06 & 3.78 & 14.50 & 29.63 & 5.83 & 21.8 & 37.1 & 52.4 & 72.6 \\
\hline \multirow[t]{2}{*}{ Figure 7} & US (P) & 10 & 95 & 7.52 & 24.27 & 2.29 & 19.69 & 28.85 & 10.61 & 46.6 & 63.4 & 80.2 & 100.0 \\
\hline & Non-US (P) & 5 & 59 & 22.05 & 20.37 & 2.11 & 16.15 & 24.59 & 9.66 & 54.8 & 68.9 & 83.1 & 100.0 \\
\hline \multirow[t]{2}{*}{ Figure 8} & US (F) & 17 & 170 & -16.12 & 23.72 & 1.21 & 21.30 & 26.14 & 19.59 & 22.1 & 38.5 & 54.9 & 76.7 \\
\hline & Non-US (F) & 10 & 118 & -12.56 & 24.16 & 0.93 & 22.31 & 26.02 & 26.08 & 26.3 & 43.1 & 59.8 & 82.0 \\
\hline
\end{tabular}

\section{Publisher's Note}

Springer Nature remains neutral with regard to jurisdictional claims in published maps and institutional affiliations.

Received: 17 February 2017 Accepted: 25 July 2017

Published online: 01 August 2017

\section{References}

* Denotes a study identified for the systematic review. ${ }^{\dagger}$ Denotes a study included in the analysis.

${ }^{* \dagger}$ Ambihapathy, C. (1983). Criminal career research in the city of Ottawa. (Unpublished doctoral dissertation). University of Ottawa, Canada.

Andresen, M. A. (2014). Environmental criminology: Evolution, theory, and practice. New York, NY: Routledge.

Auerhahn, K. (1999). Selective incapacitation and the problem of prediction. Criminology, 37(4), 703-734

Babinski, L. M., Hartsough, C. S., \& Lambert, N. M. (2001). A comparison of self-report of criminal involvement and official arrest records. Aggressive Behavior, 27, 44-54.

*Baker, L. A., Mack, W., Moffitt, T. E., \& Mednick, S. (1989). Sex differences in property crime in a Danish adoption cohort. Behavior Genetics, 19(3), 355-370.

*Barnes, J. C. (2014). Catching the really bad guys: an assessment of the efficacy of the US criminal justice system. Journal of Criminal Justice, 42(4), 338-346.

*Beaver, K. M. (2011). Genetic influences on being processed through the criminal justice system: results from a sample of adoptees. Biological Psychiatry, 69(3), 282-287.

${ }^{*}$ Beaver, K. M. (2013). The familial concentration and transmission of crime Criminal Justice and Behavior, 40(2), 139-155.

*'Beck, A. J., \& Shipley, B. E. (1987). Recidivism of young parolees. Washington, DC: US Department of Justice, Bureau of Justice Statistics.

Beel, J., \& Gipp, B. (2009). Google Scholar's ranking algorithm: an introductory overview. In B. Larsen \& J. Leta (Eds.), Proceedings of the 12th
International Conference on Scientometrics and Informetrics (Vol. 1, pp. 230-241)

*Block, C. R., Blokland, A. A., van der Werff, C., van Os, R., \& Nieuwbeerta, P. (2010). Long-term patterns of offending in women. Feminist Criminology, 5(1), 73-107.

Blumstein, A., Cohen, J., \& Farrington, D. P. (1988). Criminal career research: Its value for criminology. Criminology, 26, 1-35.

*'Brame, R., Fagan, J., Piquero, A. R., Schubert, C. A., \& Steinberg, L. (2004). Criminal careers of serious delinquents in two cities. Youth Violence and Juvenile Justice, 2(3), 256-272.

*Brame, R., Mulvey, E. P., Piquero, A. R., \& Schubert, C. A. (2014). Assessing the nature and mix of offences among serious adolescent offenders. Criminal Behaviour and Mental Health, 24(4), 254-264.

*Brennan, P., Mednick, S., \& John, R. (1989). Specialization in violence: Evidence of a criminal subgroup. Criminology, 27(3), 437-453.

*Brennan, P. A., Mednick, S. A., \& Hodgins, S. (2000). Major mental disorders and criminal violence in a Danish Birth Cohort. Archives of General Psychiatry, $57,494-500$.

*Caicedo, B., Gonçalves, H., González, D. A., \& Victora, C. G. (2010). Violent delinquency in a Brazilian birth cohort: The roles of breast feeding, early poverty and demographic factors. Paediatric and Perinatal Epidemiology, 24(1), 12-23.

*Carkin, D. M. (2014). Criminal career paths in the 1958 Philadelphia birth Cohort: Onset, progression, and desistance (Unpublished doctoral dissertation). University of Massachusetts, Lowell.

${ }^{*}$ Carrington, P. J., Matarazzo, A., \& DeSouza, P. (2005). Court careers of a Canadian birth cohort. Ottawa: Canadian Centre for Justice Statistics.

*Cernkovich, S. A., Giordano, P. C., \& Pugh, M. D. (1985). Chronic offenders: The missing cases in self-report delinquency research. Journal of Criminal Law \& Criminology, 76, 705-732.

Clarke, R. V. G. (Ed.). (1997). Situational crime prevention. Monsey, NY: Criminal Justice Press.

Clarke, R. V. (2004). Technology, criminology, and crime science. European Journal on Criminal Policy and Research, 10(1), 55-63.

Clarke, R. V., \& Eck, J. E. (2005). Crime analysis for problem solvers. Washington, DC: Center for Problem Oriented Policing. 
*Coid, J., Yang, M., Ullrich, S., Zhang, T., Roberts, A., Roberts, C., et al. (2007). Predicting and understanding risk of re-offending: The prisoner cohort study. London: Ministry of Justice.

${ }^{* \dagger}$ Collins, J. J. (1987). Some policy implications of sample arrest patterns. In M. E. Wolfgang, T. P. Thornberry, \& R. M. Figlio (Eds.), From boy to man, delinquency to crime (pp. 76-86).

${ }^{* \dagger}$ Collins, M. F., \& Wilson, R. M. (1990). Automobile theft: Estimating the size of the criminal population. Journal of Quantitative Criminology, 6(4), 395-409.

*Crowe, R. R. (1972). The adopted offspring of women criminal offenders: A study of their arrest records. Archives of General Psychiatry, 27(5), 600-603.

Cullen, F. T. (2011). Beyond adolescence-limited criminology: Choosing our future-The American Society of Criminology 2010 Sutherland address. Criminology, 49(2), 287-329.

*Davis, M., Banks, S., Fisher, W., \& Grudzinskas, A. (2004). Longitudinal patterns of offending during the transition to adulthood in youth from the mental health system. The Journal of Behavioral Health Services \& Research, 31(4), 351-366.

*DeLisi, M. (2003). Criminal careers behind bars. Behavioral Sciences \& the Law, 21(5), 653-669.

DeLisi, M., \& Piquero, A. R. (2011). New frontiers in criminal careers research, 2000-2011: A state-of-the-art review. Journal of Criminal Justice, 39(4), 289-301.

*DeLisi, M., \& Scherer, A. M. (2006). Multiple homicide offenders: Offense characteristics, social correlates, and criminal careers. Criminal Justice and Behavior, 33(3), 367-391.

*Denno, D. W. (1994). Gender, crime, and the criminal law defenses. The Journal of Criminal Law and Criminology, 85(1), 80-180.

D'Unger, A. V., Land, K. C., \& McCall, P. L. (2002). Sex differences in age patterns of delinquent/criminal careers: Results from Poisson latent class analyses of the Philadelphia cohort study. Journal of Quantitative Criminology, 18(4), 349-375.

Eck, J. E. (2001). Policing and crime event concentration. In R. F. Meier, L. W. Kennedy, \& V. F. Sacco (Eds.), The process and structure of crime: Criminal events and crime analysis (pp. 249-276).

Eck, J. E., Clarke, R. V., \& Guerette, R. T. (2007). Risky facilities: Crime concentration in homogeneous sets of establishments and facilities. Crime prevention studies (Vol. 21, pp. 225-264). Monsey, NY: Criminal Justice Press.

Eck, J. E., Lee, Y. J., O, S. H., \& Martinez, N. N. (2017). Compared to what? Estimating the relative concentration of crime at places using systematic and other reviews. Crime Science, 6(8). doi:10.1186/s40163-017-0070-4

Edelstein, A. (2016). Rethinking conceptual definitions of the criminal career and serial criminality. Trauma, Violence, \& Abuse, 17(1), 62-71.

*†'Elonheimo, H., Gyllenberg, D., Huttunen, J., Ristkari, T., Sillanmäki, L., \& Sourander, A. (2014). Criminal offending among males and females between ages 15 and 30 in a population-based nationwide 1981 birth cohort: Results from the FinnCrime Study. Journal of Adolescence, 37(8), 1269-1279.

*Facella, C. A. (1983). Female delinquency in a birth cohort (Pennsy/vania) (Unpublished doctoral dissertation). University of Pennsylvania.

Farrington, D. P. (1986). Age and crime. Crime and Justice, 7, 189-250.

Farrington, D. P. (1992). Criminal career research in the United Kingdom. The British Journal of Criminology, 32(4), 521-536.

Farrington, D. P. (2015). Cross-national comparative research on criminal careers, risk factors, crime and punishment. European Journal of Criminology, 12(4), 386-399.

*Farrington, D. P., Jolliffe, D., Hawkins, J. D., Catalano, R. F., Hill, K. G., \& Kosterman, R. (2003). Comparing delinquency careers in court records and self-reports. Criminology, 41(3), 933-958.

*Farrington, D. P., Jolliffe, D., Loeber, R., \& Homish, D. L. (2007). How many offenses are really committed per juvenile court offender? Victims and Offenders, 2(3), 227-249.

* ${ }^{\dagger}$ Farrington, D. P., \& Maughan, B. (1999). Criminal careers of two London cohorts. Criminal Behaviour and Mental Health, 9(1), 91-106.

*Farrington, D. P., \& West, D. J. (1990). The Cambridge study in delinquent development: A long-term follow-up of 411 London males. Kriminalität (pp. 115-138). New York, NY: Springer-Verlag.

*Farrington, D. P., \& Wikstrom, P. O. H. (1994). Criminal careers in London and Stockholm: A cross-national comparative study. In E. G. M. Weitekamp
\& H.-J. Kerner (Eds.), Cross-national longitudinal research on human development and criminal behavior (pp. 65-89). Boston, MA: Kluwer.

*Fergusson, D. M., Lynskey, M. T., \& Horwood, L. (1996). Alcohol misuse and juvenile offending in adolescence. Addiction, 91(4), 483-494.

*Fischer, B., Medved, W., Kirst, M., \& Rehm, J. (2001). Illicit opiates and crime: Results of an untreated user cohort study in Toronto. Canadian Journal of Criminology, 43, 197-217.

*Fisher, W. H., Roy-Bujnowski, K. M., Grudzinskas, A. J., Jr., Clayfield, J. C., Banks, S. M., \& Wolff, N. (2006). Patterns and prevalence of arrest in a statewide cohort of mental health care consumers. Psychiatric Services, 57(11), 1623-1628.

*Fry, L. J. (1985). Drug Abuse and crime in a Swedish birth cohort. British Journal of Criminology, 25(1), 46-59.

Gendreau, P. (1996). Offender rehabilitation: What we know and what needs to be done. Criminal Justice and behavior, 23(1), 144-161.

${ }^{* \dagger}$ Glueck, S., \& Glueck, E. (1950). Unraveling juvenile delinquency. Cambridge, MA: Harvard University Press.

*Graham, J. \& Bowling, B. (1995). Young people and crime. Research Study, 145 London, UK: Home Office.

Greenwood, P. W., \& Abrahamse, A. F. (1982). Selective incapacitation. Santa Monica, CA: Rand Corporation.

Guttridge, P., Gabrielli, W. F., Jr., Mednick, S. A., \& Van Dusen, K. T. (1983). Criminal violence in a birth cohort. In K. T. Van Dusen \& S. A. Mednick (Eds.), Prospective studies of crime and delinquency (pp. 211-224). Boston, MA: Kluwer-Nijhoff.

*Haas, H., Farrington, D. P., Killias, M., \& Sattar, G. (2004). The impact of different family configurations on delinquency. British Journal of Criminology, 44(4), 520-532.

${ }^{*}+$ Hamparian, D., Schuster, R., Dinitz, S., \& Conrad, J. P. (1978). The violent few. Lexington, MA: DC Heath.

*Hamparian, D. M., Davis, J. M., Jacobson, J. M., \& McGraw, R. E. (1985). The young criminal years of the violent few. Washington, DC: Department of Justice.

* Harer, M. D. (1995). Recidivism among federal prisoners released in 1987. Journal of Correctional Education, 46(3), 98-128.

Hirschi, T., \& Gottfredson, M. (1983). Age and the explanation of crime. American Journal of Sociology, 89(3), 552-584.

*Høgh, E., \& Wolf, P. (1983). Violent crime in a birth cohort: Copenhagen 1953-1977. In K. T. Van Dusen \& S. A. Mednick (Eds.), Prospective studies of crime and delinquency (pp. 249-267). Boston, MA: Kluwer-Nijhoff.

*Juon, H. S., Doherty, E. E., \& Ensminger, M. E. (2006). Childhood behavior and adult criminality: Cluster analysis in a prospective study of African Americans. Journal of Quantitative Criminology, 22(3), 193-214.

*Kempf-Leonard, K., Tracy, P. E., \& Howell, J. C. (2001). Serious, violent, and chronic juvenile offenders: The relationship of delinquency career types to adult criminality. Justice Quarterly, 18(3), 449-478.

Kirk, D. S. (2006). Examining the divergence across self-report and official data sources on inferences about the adolescent life-course of crime. Journal of Quantitative Criminology, 22(2), 107-129.

Koch, R. (1998). The 80/20 principle. New York, NY: Doubleday.

Lee, Y. J., Eck, J. E., O, S. H., \& Martinez, N. N. (2017). How concentrated is crime at places? A systematic review from 1970 to 2015. Crime Science, 6(6). doi:10.1186/s40163-017-0069-x.

Lilly, J. R., Cullen, F. T., \& Ball, R. A. (2015). Criminological theory: Context and consequences (6th ed.). Los Angeles, CA: Sage.

${ }^{*}{ }^{\dagger}$ Liu, J., Messner, S. F., \& Liska, A. E. (1997). Chronic offenders in China. International Criminal Justice Review, 7(1), 31-45.

Lowenkamp, C. T., \& Latessa, E. J. (2004). Understanding the risk principle: How and why correctional interventions can harm low-risk offenders. Topics in Community Corrections, 2004, 3-8.

*Mazerolle, P., Brame, R., Paternoster, R., Piquero, A., \& Dean, C. (2000). Onset age, persistence, and offending versatility: Comparisons across gender. Criminology, 38(4), 1143-1172.

${ }^{* \dagger}$ Mednick, S. A., Gabrielli, W. F., \& Hutchings, B. (1984). Genetic influences in criminal convictions: Evidence from an adoption cohort. Science, 224(4651), 891-894.

${ }^{* \dagger}$ Nevares, D., Wolfgang, M. E., Tracy, P., \& Aurand, S. (1990). Delinquency in Puerto Rico. London: Greenwood Press.

O, S. H., Martinez, N. N., Lee, Y. J., \& Eck, J. E. (2017). How concentrated is crime among victims? A systematic review from 1977 to 2014. Crime Science. 6(9). doi:10.1186/s40163-017-0071-3. 
*Paradis, A. D., Fitzmaurice, G. M., Koenen, K. C., \& Buka, S. L. (2010). Maternal smoking during pregnancy and criminal offending among adult offspring. Journal of Epidemiology and Community Health, 65(12), 1145-1150.

Petersilia, J. (1980). Criminal career research: A review of recent evidence. Crime and Justice, 2, 321-379.

*Peterson, M. A., Braiker, H. B., \& Polich, S. (1980). Doing crime: A survey of California prison inmates. Santa Monica, CA: Rand Corporation.

${ }^{*}$ Piper, E. S. (1983). Patterns of violent juvenile recidivism. (Unpublished doctoral dissertation). University of Pennsylvania.

Piper, E. S. (1985). Violent recidivism and chronicity in the 1958 Philadelphia cohort. Journal of Quantitative Criminology, 1(4), 319-344.

${ }^{*}$ Piquero, A. R. (2000). Assessing the relationships between gender, chronicity, seriousness, and offense skewness in criminal offending. Journal of Criminal Justice, 28(2), 103-115.

*+Piquero, A. R., \& Buka, S. L. (2002). Linking juvenile and adult patterns of criminal activity in the Providence cohort of the National Collaborative Perinatal Project. Journal of Criminal Justice, 30(4), 259-272.

Piquero, A. R., Farrington, D. P., \& Blumstein, A. (2003). The criminal career paradigm. Crime and Justice, 30, 359-506.

${ }^{*}$ Piquero, A. R., Farrington, D. P., \& Blumstein, A. (2007). Key issues in criminal career research: New analyses of the Cambridge Study in Delinquent Development. Cambridge: Cambridge University Press.

*Piquero, A. R., Farrington, D. P., Jennings, W. G., Diamond, B., \& Craig, J. (2012). Sex offenders and sex offending in the Cambridge study in delinquent development: Prevalence, frequency, specialization, recidivism, and (dis)continuity over the life-course. Journal of Crime and Justice, 35(3), $412-426$.

${ }^{*}$ Piquero, A. R., Piquero, N. L., Terry, K. J., Youstin, T., \& Nobles, M. (2008). Uncollaring the criminal understanding criminal careers of criminal clerics. Criminal Justice and Behavior, 35(5), 583-599.

*Prime, J., White, S., Liriano, S., \& Patel, K. (2001). Criminal careers of those born between 1953 and 1978. London: Home Office.

Rocque, M., Posick, C., \& Hoyle, J. (2015a). Age and crime. In W. G. Jennings (Ed.), Encyclopedia of crime and punishment (pp. 1-8). Malden, MA: Wiley-Blackwell.

Rocque, M., Posick, C., Marshall, I. H., \& Piquero, A. R. (2015b). A comparative, cross-cultural criminal career analysis. European Journal of Criminology, 12(4), 400-419.

*'Sampson, R. J., \& Laub, J. H. (2003). Life-course desisters? Trajectories of crime among delinquent boys followed to age 70. Criminology, 41(3), 555-592.

${ }^{*}$ Schumacher, M., \& Kurz, G. A. (2000). The $8 \%$ solution: Preventing serious, repeat juvenile crime. Thousand Oaks: Sage Publications.

*Schwaner, S. L. (1998). Patterns of violent specialization: Predictors of recidivism for a cohort of parolees. American Journal of Criminal Justice, 23(1), $1-17$

Scott, M. (2005). Policing for prevention: Shifting and sharing the responsibility to address public safety problems. In N. Tilley (Ed.), Handbook of crime prevention and community safety. Cullompton: Willan.
*'Shannon, L. W., McKim, J. L., Curry, J. P., \& Haffner, L. J. (1988). Criminal career continuity: Its social context. New York, NY: Human Sciences Press.

Shaw, C. R., \& McKay, H. D. (1942). Juvenile delinquency and urban areas. Chicago, IL: University of Chicago Press.

*'Skrzypiec, G., Castle, C., \& Wundersitz, J. (2005). Offending at 16 to 20 years of age: Identifying youth for intensive intervention. Adelaide: Office of Crime Statistics and Research.

*Snyder, H. N. (1988). Court careers of juvenile offenders. Washington, DC: Office of Juvenile Justice and Delinquency Prevention.

Spelman, W. (1986). The depth of a dangerous temptation: Another look at selective incapacitation. Washington, DC: US Department of Justice.

Spelman, W., \& Eck, J. E. (1989). Sitting ducks, ravenous wolves and helping hands: New approaches to urban policing. In B. Lyndon (Ed.), Austin: Johnson School of Public Affairs, University of Texas at Austin.

*Stattin, H., Magnusson, D., \& Reichel, H. (1989). Criminal activity at different ages: A study based on a Swedish longitudinal research population. British Journal of Criminology, 29(4), 368-385.

*Tillman, R. (1987). The size of the "criminal population": The prevalence and incidence of adult arrest. Criminology, 25(3), 561-579.

*Tracy, P. E., Wolfgang, M. E., \& Figlio, R. M. (1990). Delinquency careers in two birth cohorts. New York, NY: Plenum Press.

*†Van Dusen, K. T., \& Mednick, S. A. (1984). A comparison of delinquency in Copenhagen and Philadelphia. Washington, DC.: National Institute of Justice.

${ }^{*}$ WWarren, M. Q., \& Rosenbaum, J. L. (1986). Criminal careers of female offenders. Criminal Justice and Behavior, 13(4), 393-418.

*West, D. J., \& Farrington, D. P. (1973). Who becomes delinquent? Second report of the Cambridge Study in Delinquent Development. London: Heinemann.

Weisburd, D. (2015). The law of crime concentration and the criminology of place. Criminology, 53(2), 133-157.

Weisburd, D., Bushway, S., Lum, C., \& Yang, S. M. (2004). Trajectories of crime at places: A longitudinal study of street segments in the city of Seattle. Criminology, 42(2), 283-322.

Weisburd, D., Groff, E. R., \& Yang, S.-M. (2012). The criminology of place: Street segments and our understanding of the crime problem. New York, NY: Oxford.

*Wikström, P. O. H. (1990). Age and crime in a Stockholm cohort. Journal of Quantitative Criminology, 6(1), 61-84.

Wilcox, P., Gialopsos, B. M., \& Land, K. (2012). Multilevel criminal opportunity. In F. T. Cullen \& P. Wilcox (Eds.), Oxford handbook of criminological theory (pp. 579-601). Oxford: New York, NY

*Wolf, P. (1962). Crime and social class in Denmark. The British Journal of Criminology, 3(1), 5-17.

*†Wolfgang, M. E., Figlio, R. M., \& Sellin, T. M. (1972). Delinquency in a birth cohort. Chicago: University of Chicago Press.

${ }^{*}$ Y Yunker, J., Bombach, V., \& Meyerhoff, C. (2001). Chronic offenders. St. Paul, MN: Office of the Legislative Auditor.

*Zimring, F. E., Jennings, W. G., Piquero, A. R., \& Hays, S. (2009). Investigating the continuity of sex offending: Evidence from the second Philadelphia birth cohort. Justice Quarterly, 26(1), 58-76.

\section{Submit your manuscript to a SpringerOpen ${ }^{\odot}$ journal and benefit from:}

- Convenient online submission

- Rigorous peer review

- Open access: articles freely available online

- High visibility within the field

- Retaining the copyright to your article

Submit your next manuscript at $\boldsymbol{\Delta}$ springeropen.com 